\title{
Aplicando la interdisciplinariedad en el aula: La mujer transitando espacios y rompiendo moldes (siglos XV-XX)
}

\section{Applyng interdisciplinarity in the classroom: Women transiting spaces and breaking molds (XV-XX centuries)}

\author{
Yolanda Victoria Olmedo Sánchez, ${ }^{1}$ Soledad Gómez Navarro, ${ }^{2}$ Antonio Jesús \\ González Torrico, ${ }^{3}$ Marta María Manchado López, ${ }^{4}$ Daniel David Martínez Romera ${ }^{5}$ \& \\ Francisco Mellado Calderón. ${ }^{6}$
}

Fecha de recepción: 23/09/2019; Fecha de revisión: 04/10/2019; Fecha de aceptación: 28/11/2019

Cómo citar este artículo:

Olmedo Sánchez, Y.V., Gómez Navarro, S., González Torrico, A.J. Manchado López M.M., Martínez Romera, D.D. \& Mellado Calderón, F. (2019). Aplicando la interdisciplinariedad en el aula: La mujer transitando espacio y rompiendo moldes (siglos XV-XX). Revista de Innovación y Buenas Prácticas Docentes, 8(4), 1-15.

Autor de Correspondencia: aa1olsay@uco.es

\section{Resumen:}

El proyecto se centra en el estudio del largo camino recorrido por la mujer desde el ámbito doméstico hasta el ámbito extradoméstico o público, desde los tiempos modernos a la actualidad. Abordándose desde la transversalidad que permiten diversas disciplinas (Historia Moderna, Historia de América, Historia del Arte y Didáctica de las Ciencias Sociales), dicho trabajo permite ser analizado desde diferentes perspectivas: mujeres que, ya desde las centurias modernas, se atreven a transgredir las normas de comportamiento vigentes; que participan en acontecimientos claves de la contemporaneidad como la revolución industrial, los movimientos obreros, el activismo político; que adquieren relevancia en el mecenazgo artístico o que, en calidad de pintoras y escultoras, convierten el arte en su profesión; así como mujeres que van asumiendo un creciente protagonismo en la educación, en la instrucción de algunas disciplinas o en la evolución de los Derechos Humanos.

Palabras clave: ámbito público, estudio interdisciplinar, mujer, siglos XV-XX.

\footnotetext{
1 Universidad de Córdoba (España), aa1olsay@uco.es CÓDIGO ORCID: https://orcid.org/0000-00019787-4553

Universidad de Córdoba (España), hi1gonas@uco.es; CÓDIGO ORCID: https://orcid.org/0000-00021962-0950

${ }^{3}$ Universidad Internacional de La Rioja (España). Durante la realización del proyecto perteneció al Centro de Magisterio Sagrado Corazón, adscrito a la Universidad de Córdoba (España), ajtorrico1970@gmail.com;

4 Universidad de Córdoba (España), hi1malom@uco.es; CÓDIGO ORCID: https://orcid.org/0000-00017926-038X

${ }^{5}$ Universidad de Cádiz (España), Durante la realización del proyecto perteneció a la Universidad de Málaga (España), danieldavid.martinez@uca.es.; CÓDIGO ORCID: https://orcid.org/0000-0003-48957955

6 Diputación Provincial de Córdoba (España), Durante la realización del proyecto fue colaborador honorario del Departamento de Historia del Arte, Arqueología y Música. Universidad de Córdoba (España), pacomelcal@hotmail.com; CÓDIGO ORCID: https://orcid.org/0000-0003-3663-0445
} 


\begin{abstract}
:
The project focuses on the study of the long road traveled by women from the domestic sphere to the extra-domestic or public sphere, from modern times to the present. Approaching from the transversality that allows various disciplines (Modern History, American History, Art History and Didactics of the Social Sciences), this work can be analyzed from different perspectives: women who, since the modern centuries, come to transgress the current standards of behavior; who participate in key events of contemporaneity such as the industrial revolution, the workers' movements, political activism; hat acquire relevance in artistic patronage or that, as painters and sculptors, make art their profession; as well as women who are assuming a growing role in education, in the education of some disciplines or in the evolution of Human Rights.
\end{abstract}

Key Words: public ambit, interdisciplinary study, woman, XV-XX centuries.

\title{
1. INTRODUCCIÓN
}

Uno de los principales logros historiográficos de las últimas décadas ha estado protagonizado por los estudios de género. Tal panorama, bastante generalizado en las disciplinas pertenecientes al ámbito de las Humanidades, ha sido patente tanto a nivel nacional como a nivel internacional. Hemos de destacar las aportaciones de algunas historiadoras como la norteamericana Joan Wallach Scott o la irlandesa afincada en España Mary Nash. Ambas son autoras de numerosas publicaciones centradas en la historia de la mujer. Importantes son también las investigaciones efectuadas en nuestro país a cargo de Cristina Segura Graiño, Gloria A. Franco Rubio, Margarita Birriel Salcedo o Soledad Gómez Navarro. En el ámbito de la Historia del Arte hemos de destacar las contribuciones de Linda Nochlin, Mary Garrard o Griselda Pollock; y en lo que respecta a España, las aportaciones de Estrella de Diego, Pilar Muñoz López, Teresa Sauret o Noelia García Pérez.

Asimismo, recientes investigaciones en nuestro país han planteado los estudios de género desde una perspectiva interdisciplinar con óptimos resultados. Tal es el caso de La arquitectura en Andalucía desde una perspectiva de género (GENARQ, HUM. 5709), proyecto de excelencia de la Universidad de Granada, subvencionado por la Junta de Andalucía. Del mismo resultó la publicación Arquitectura y mujeres en la historia, bajo la edición de $\mathrm{M}^{\mathrm{a}}$ Elena Díez Jorge. Cabe destacar también un nutrido número de publicaciones, resultado de una serie de estudios interdisciplinares abordados en proyectos de investigación o reuniones científicas. Igualmente, hemos de subrayar las actividades y publicaciones impulsadas por la Asociación Española de Investigación de Historia de las Mujeres, el Instituto Universitario de Investigación de Estudios de las Mujeres y de Género de la Universidad de Granada; así como algunos másteres ofertados por algunas universidades españolas sobre temas de género, bajo una perspectiva multidisciplinar.

Sin embargo, todavía queda mucho por hacer en el marco de los estudios de género. Igualmente, no debemos olvidar que los resultados de la investigación han de ofrecerse a la educación, con el fin de que la sociedad pueda participar de los logros de la ciencia. A este respecto ha de entenderse el papel de la Universidad, cobrando especial sentido el campo de las Humanidades en relación a determinados temas de actualidad. Hemos de subrayar la importancia del conocimiento de la Historia, en la medida en que puede contribuir positivamente a la transformación del presente y del futuro. 
Conscientes de tal premisa y comprometidos con el deseo de fomentar los estudios sobre las mujeres y darlos a conocer al alumnado, surgió este proyecto de innovación docente. No es el primero abordado por algunos de los integrantes del mismo, ya que durante el curso académico 2013-2014 participaron igualmente en un proyecto de innovación educativa, centrado a la vida cotidiana de las mujeres: Trabajando la transversalidad en el aula: mujer y vida cotidiana en la construcción de la cultura occidental desde el arte, la historia y la literatura, bajo la coordinación de la Dra. Soledad Gómez Navarro. Posteriormente, durante el curso académico 20162017, vuelven a trabajar en los estudios de género con el proyecto: Aplicación curricular del estudio interdisciplinar de la mujer como sujeto activo (siglos XV-XIX), bajo la coordinación de la Dra. Yolanda Victoria Olmedo Sánchez. Tales proyectos constituyeron ya una respuesta a la escasa presencia de los estudios de las mujeres en los Grados que se imparten en la Facultad de Filosofía y Letras de la Universidad de Córdoba. Una realidad que se contrapone al manifiesto interés del alumnado por los temas de género, razón que llevó de nuevo a emprender un nuevo proyecto de innovación docente durante el curso académico 2017-2018: Aplicando la interdisciplinariedad en el aula: la mujer transitando espacios y rompiendo moldes (siglos $X V-X X$ ), coordinado también por la Dra. Olmedo Sánchez.

\section{DESARROLLO DE LA EXPERIENCIA DE INNOVACIÓN}

Los proyectos de innovación docente abordados con anterioridad y a los que ya se han hecho referencia, han constituido una sólida base para afrontar esta nueva experiencia centrada, una vez más, en la temática de género. En el marco de diversas asignaturas relacionadas con la Historia Moderna, la Historia de América, la Historia del Arte y la Didáctica de las Ciencias Sociales, varios han sido los objetivos perseguidos por los integrantes del presente proyecto de innovación docente:

1. Partiendo de las perspectivas que ofrecen las disciplinas indicadas y tomando como base los contenidos teóricos y prácticos abordados en la docencia, se ha pretendido suscitar en el alumnado la atención y el interés por la figura de la mujer y su protagonismo en la Historia en general.

2. El estudio de la mujer durante las centurias modernas y la contemporaneidad, desde el análisis ofrecido por la Historia Social y la Historia de la Cultura. Se ha pretendido que el alumnado entienda dicho enunciado, ya que las mujeres han de ser analizadas desde el enfoque que ofrece el orden social y cultural, con el fin de obtener una visión más completa y objetiva de la Historia.

3. Analizar con el alumnado el concepto de "vida cotidiana" y, dentro del mismo, las nociones y contenidos de espacio doméstico y espacio extradoméstico. En relación a este punto, estudiar algunos aspectos concretos de la "vida cotidiana" marcados, precisamente, por la huella femenina, tales como: mujeres y familia, mujeres y relaciones sociales, mujeres y religión, mujeres y trabajo, mujeres y política, mujeres y educación (maestras y profesoras), mujeres y derechos humanos, así como los diversos análisis que permiten el binomio mujeres y arte (promoción, creación y enseñanza artística). 
4. Plantear y estudiar la diversidad de fuentes históricas y artísticas que permiten evidenciar la activa participación de la mujer en el orden social y cultural: documentos de diversa tipología (notariales, epistolares, etc.); fuentes bibliográficas, periodísticas y literarias; obras artísticas (pinturas, dibujos, grabados, esculturas...), así como otras manifestaciones artísticas de gran valor documental para el estudio de la época contemporánea como el cartel, la fotografía y la filmografía.

5. En relación a los puntos anteriores, estudiar y valorar aquellas figuras femeninas que, desde diversos ámbitos, se rebelaron con sus conductas a las normas vigentes de comportamiento en las épocas en las que vivieron.

El plan metodológico propuesto para el desarrollo de esta experiencia de innovación docente ha sido práctico, fundamentalmente. Como base se ha partido de las guías docentes (estructuradas desde el punto de vista curricular en contenidos teóricos y prácticos), correspondientes a las diversas asignaturas impartidas por los docentes integrantes del proyecto. Partiendo de tal premisa, la intención ha sido recopilar numerosos testimonios, huellas y evidencias de muy diversa naturaleza, atendiendo a la riqueza y variedad de fuentes empleadas y desde la transversalidad que ofrecen las disciplinas contempladas en el proyecto. Todo ello con el fin de contextualizar la vida cotidiana femenina y ahondar en la trayectoria recorrida por las mujeres desde el ámbito doméstico hasta el ámbito extradoméstico o público

\subsection{Precisión metodológica}

Se expone a continuación la metodología y material empleados por los docentes integrantes del proyecto, en el marco de cada una de las disciplinas contempladas en el mismo:

En lo referente a la Historia Moderna, tres son las aportaciones realizadas por la profesora Gómez Navarro:

En primer lugar, el trabajo con el alumnado en la asignatura Historia Social en la Edad Moderna, optativa de cuarto curso del Grado de Historia. En esta primera acción la contribución ha sido doble: En el desarrollo general de la materia y en dos de sus temas en particular; y en el trabajo de curso que el alumnado ha realizado.

Por lo que concierne a la primera tarea se ha analizado el papel de la mujer en dos temas: Sobre instituciones sociales básicas y nuevos sujetos historiográficos o sea, familia y mujer-; y, sobre la Iglesia católica como institución social y de poder, porque las monjas y religiosas también son mujeres. Por consiguiente, en su análisis y estudio ha de aplicarse también la perspectiva de género. El dossier de materiales que constituye la base principal del trabajo del docente y alumnado, dentro y fuera del aula, contiene bibliografía específica del tema en cuestión; esquema básico que se desarrolla en clase; y materiales de apoyo que se van analizando y comentando entre clases teóricas y prácticas.

Respecto al trabajo de curso realizado por el alumnado, ha consistido en la consulta, sistematización y estudio de fuentes escritas (los libros de Familias de Seglares y Familias de Eclesiásticos, los libros de lo personal, del catastro de Ensenada); o de fuentes artísticas, sobre todo pintura y literatura de la Europa del Antiguo Régimen. En cualquiera de las dos opciones, se ha hecho presente la mujer que se ha examinado desde el punto de vista social, teniendo en cuenta el enfoque estamental (según la organización social del Antiguo Régimen, y que pone el foco en el "privilegio", estados sociales privilegiados como el nobiliario y el eclesiástico, o no, como el tercer estado); la morfología social (que se presenta diversa y aun 
heterogénea en los distintos agregados y colectivos); y la dinámica social, es decir, el conflicto, intra e interestamental, y la evolución hasta llegar a las sociedades liberales que clausuran la época moderna.

En segundo lugar, la dirección del Trabajo Fin de Grado, en el Grado de Historia, de la alumna Lucía Requena Ráez. Titulado "Aproximación al divorcio en la Córdoba moderna: Norma y realidad", constituye un innovador y pionero interés investigador al tocar una parcela prácticamente virgen en la historiografía modernista cordobesa. En dicho estudio se ha tratado de realizar un primer acercamiento jurídico y social al divorcio canónico, a través del matrimonio como institución que acoge tal situación como una de sus formas de ruptura, así como del proceso legal que lo permite. Para ello, dos fuentes han sido fundamentales en este TFG. Por una parte, la legislación canónica y civil que rige el sacramento, antes, en y después de Trento, en Constituciones Sinodales, actas conciliares y normativa laica, y no solo para conocer el marco conceptual ordenador de la institución matrimonial y en que actúan conjuntamente poder eclesiástico y civil; sino también, y sobre todo, para comprobar cómo se acomoda el desvío o la ruptura del vínculo matrimonial en forma de divorcio canónico, proceso sin duda minoritario porque así suele serlo la transgresión, pero lo que ya es, per se, altamente interesante social y culturalmente. Por otra parte, el examen minucioso de más de cien expedientes de divorcio del Archivo Diocesano, con los que poder establecer, entre otras variables, la extensión y duración del fenómeno, su sociología y, especialmente, las motivaciones que lo desencadenan, a fin de conocer su posible relación con el medio geográfico, determinadas coyunturas y la situación social, y de intentar descubrir y evidenciar el papel, la imagen y, en su caso, protagonismo de las mujeres en procesos traumáticos de la tipología y naturaleza del que nos ocupa.

En tercer lugar, las propias investigaciones de la profesora Gómez Navarro sobre el sujeto histórico constitutivo del proyecto de innovación docente, publicadas entre los años 2017 y 2018 (recogidas en el apartado Referencias), así como otros estudios actualmente en prensa.

En lo que respecta a la Historia de América, la actividad docente de la profesora Manchado López ha sido concebida como complemento y desarrollo de aspectos que no pudieron ser abordados en el marco del proyecto de innovación docente: Aplicación curricular del estudio interdisciplinar de la mujer como sujeto activo (siglos XV-XIX), durante el curso académico 2016-2017. Ha supuesto, por lo tanto, una profundización en el empeño de difundir desde el aula la presencia y acción de la mujer en la Historia de América, desde una perspectiva netamente historiográfica.

De este modo, se ha diseñado y desarrollado una actividad docente para la asignatura España y su proyección americana, la cual se ofrece dentro del repertorio de asignaturas optativas del Grado de Historia, cursándose en el cuarto curso del mismo. La actividad diseñada ha sido abordada en dos sesiones de hora y media cada una, una vez tratados los primeros temas del programa de la asignatura y tras estudiar las características de la sociedad española de Manila en los siglos XVI y XVII.

En la primera sesión el foco de atención se ha centrado en las estrategias matrimoniales desplegadas por los sectores dominantes de la sociedad española, a fin de fortalecer su posición social, económica y sus ansias de poder. El choque de intereses contrapuestos, la transgresión de las leyes que prohibían los vínculos familiares de funcionarios públicos con miembros de la sociedad local, y el espacio de decisión de la mujer son algunos de los aspectos planteados en esta sesión, para cuyo desarrollo se ha partido de una bibliografía de carácter general y de otra específica, la 
cual se relaciona al final de esta memoria. La primera sesión se ha desarrollado conforme al siguiente esquema:

1- Exposición introductoria del tema, centrada en los siguientes aspectos:

1.1. El contexto histórico: síntesis de las características y situación de la sociedad española establecida en Manila. (Repaso de lo estudiado en el tema 3).

1.2. Dinámica social y dinámica familiar. Los intereses y las posibilidades de "casar bien" en la frontera oriental de la Monarquía Hispánica.

1.3. El marco jurídico.

1.4. El espacio de decisión de la mujer: límites y posibilidades.

2- Análisis de documentos seleccionados sobre el caso de las estrategias matrimoniales de los oidores de la Audiencia de Manila. Dicho trabajo se ha realizado a través del análisis y comentario de documentos disponibles en el Portal PARES (Carta de don Santiago de Vera, presidente de la audiencia, al arzobispo. Manila, 20 de junio de 1585. AGI, Filipinas, 6, R.6, N.58; Fragmento de carta del oidor don Juan Manuel de la Vega. Manila, 28 de febrero de 1608. AGI, Filipinas, 20, R.2, N.19).

3- Debate y extracción de conclusiones.

En la segunda sesión se ha abordado un tema complementario del anterior: la violencia ejercida sobre la mujer cuando se consideraba que su comportamiento no se ajustaba a las normas sociales y familiares. Dicha violencia adoptaba formas diversas que iban desde la coacción al asesinato, siendo esta última por su espectacularidad la que ha dejado una huella más marcada en la documentación. A este respecto, se ha centrado la atención en la violencia doméstica, particularmente en tres casos que ejemplifican conflictos conyugales y paterno-filiales. El punto de partida vuelve a ser una recapitulación acerca de las características de la sociedad de la época, prestando una especial atención a la consideración jurídica y social de estos episodios. La actividad se ha desarrollado según el siguiente esquema:

1- Exposición introductoria del tema, centrada en los siguientes aspectos:

1.1-El papel y valor de la mujer en la sociedad. ¿Era Filipinas un caso especial?

1.2- La violencia contra la mujer en el contexto doméstico y su reflejo en la documentación y la historiografía.

2- Análisis de fuentes documentales seleccionadas a través del Portal PARES. Se trata de documentos relativos a los casos de doña Catalina María Zambrana, mujer del gobernador don Alonso Fajardo de Tenza, asesinada por éste por sospechas de infidelidad (Carta del gobernador Alonso Fajardo al rey. Manila, 15 de junio de 1621. AGI, Filipinas, 7, R.5, N.63); doña Juliana de Morga, hija del oidor don Antonio de Morga, maltratada por sus padres para evitar su matrimonio desigual y contrario a las leyes (Declaración jurada de doña Juana de Briviesca, esposa de don Antonio de Morga. Manila, 19 de junio de 1602. AGI, Filipinas, 7, R.1, N.1); y de la primera mujer del adelantado don Esteban Rodríguez de Figueroa, asesinada por adulterio (Informe del fiscal de la Audiencia de Manila al rey. Manila, 15 de julio de 1589. AGI, Filipinas, 18A, R.7, N.49). En este apartado se reflexiona particularmente sobre la consideración social de la violencia sobre la mujer, a partir de valoraciones de otras fuentes coetáneas.

3-Debate y extracción de conclusiones.

En lo que concierne a las Historia del Arte varias han sido las aportaciones de la profesora Olmedo Sánchez, aplicadas al proyecto de innovación docente: 
En primer lugar, el trabajo con el alumnado en tres asignaturas pertenecientes al Grado de Historia del Arte: Proyección del arte español en Hispanoamérica, Artes decorativas y aplicadas entre los siglos XV y XVIII, materias que se imparten en el segundo curso; y La génesis del arte contemporáneo, materia correspondiente al tercer curso.

En la asignatura Proyección del arte español en Hispanoamérica, se ha estudiado la dimensión privada y pública de algunas mujeres. El punto de partida ha consistido en el análisis y comentario de diversos retratos pictóricos de féminas pertenecientes a la elite social mexicana del siglo XVIII. Tal es el caso de los retratos de Ana María de la Campa y Cos y Ceballos (Condesa de San Mateo de Valparaíso y Marquesa de Jaral de Berrio), así como de otras damas novohispanas, a cargo de pintores como Andrés de Islas e Ignacio María Barreda. Dichos retratos sitúan a las mujeres en el ámbito privado, si bien tienen una clara intencionalidad pública: servir de modelo y referente para las mujeres criollas de sucesivas generaciones, dentro del orden establecido por la sociedad colonial.

En la asignatura Artes decorativas y aplicadas entre los siglos XV y XVIII, siguiendo en la línea iniciada en el proyecto de innovación docente del pasado curso académico 2016-17, se ha proseguido con el estudio de la mujer y su relación con las artes decorativas y aplicadas. En tal sentido, se ha analizado el papel de la mujer como promotora artística, continuando con el estudio de la figura de Isabella d'Este, marquesa de Mantua (1474-1539). Su mecenazgo artístico abarcó también el campo de las artes decorativas y aplicadas, habiéndose abordado, en esta ocasión, las piezas de joyería que pertenecieron a esta noble italiana y que están en consonancia con su condición de marquesa de Mantua y, por ende, con su imagen pública. Igualmente, en relación al ámbito de la joyería, se ha estudiado la figura de la archiduquesa Ana de Austria, conocida también como Ana de Habsburgo (1528-1590), esposa de Alberto V, elector de Baviera. A este respecto, se ha prestado especial atención al libro de joyas de esta noble pareja, un interesante manuscrito ilustrado por el artista alemán Hans Mielich en el que se recogen con gran precisión diversas piezas (collares, colgantes, pulseras, broches, pendientes, etc.), que pertenecieron a esta dama y que se justifican por su condición social e imagen pública. En lo concerniente al ámbito hispano se ha abordado la figura de Bárbara de Braganza (1711-1758), esposa del monarca Fernando VI, con el estudio de joyas y otros enseres de esta reina, relacionados con su imagen pública. Tal es el caso de la silla de manos de madera tallada, dorada y pintada, obra del artista italiano Corrado Giaquinto, conservada actualmente en el Palacio Real de Madrid.

Al igual que en el proyecto de innovación docente del pasado curso 2016-17, los contenidos de la asignatura La génesis del arte contemporáneo han vuelto a ser fundamentales para plantear la temática de género. La materia de dicha asignatura se centra en las creaciones artísticas de un periodo histórico de gran importancia: los comienzos del mundo contemporáneo. Se trata de una época histórica convulsa, tras la caída del Antiguo Régimen, el ascenso de la burguesía y la revolución industrial, en la que se advierte el creciente protagonismo que va adquiriendo la mujer en el ámbito social.

En tal sentido, la figura femenina ha sido estudiada partiendo del comentario de obras artísticas protagonizadas por mujeres que actúan no solo en el ámbito privado o doméstico, sino también el ámbito público, asumiendo distintos roles. Muchas transitan por calles, plazas, jardines, mercados, cafés, cabarets, etc., dada la importancia que adquiere el medio urbano en los comienzos de la época contemporánea. A este respecto, tanto en las clases teóricas como en las clases 
prácticas se han analizado pinturas, así como algunas esculturas, que ofrecen una visión del protagonismo femenino en este interesante período histórico. Artistas como Jacques Louis David, Gustave Courbet, Honoré Daumier, Richard Redgrave, Constantin Meunier, Edouard Manet, Edgar Degas, Camille Pissarro, Henri de Toulouse-Lautrec, Edward Munch, Pablo Picasso, entre otros, ofrecen una amplia visión de la mujer de la nobleza y la burguesía; de la mujer trabajadora, así como de la mujer fatal y la prostituta.

En relación a este último punto, una clase práctica se ha centrado en el análisis de la representación del cuerpo femenino en la obra de Gustav Klimt y de su discípulo Egon Schiele, partiendo de la lectura de un artículo de la investigadora Carla Carmona Escalera sobre dicho tema, en el que se ofrecen dos concepciones distintas de mujer.

En los comienzos del mundo contemporáneo va perfilándose la figura de la mujer artista, que con dificultades pasa del ámbito doméstico (en el que la creación artística es entendida como tarea diletante), al ámbito público con el fin de hacer del arte su profesión. A este respecto, en las clases prácticas han sido abordadas las figuras de numerosas artistas. La relación de mujeres pintoras ha sido amplia: Adélaïde Labille-Guiard, Constance Mayer, Marie-Guillermine Benois, Henriette Lorimier, Emily Mary Osborn, Marie Bracquemond, Berthe Morisot, Mary Cassat, Eva Gonzalès, Elizabeth Jane Gardner Bouguereau, Olga Boznańska, entre otras. Se han analizado las imágenes de mujeres ofrecidas por estas pintoras, que responden frecuentemente a tipos femeninos de la época o retratos. Se han analizado también los autorretratos realizados por algunas de estas pintoras, dado que más allá de su valor estético como obra de arte suponen interesantes documentos históricos. A través de los mismos, queda patente el manifiesto deseo de reafirmación por parte dichas pintoras en su dedicación artística. Asimismo, han sido estudiadas algunas escultoras como la francesa Camille Claudel o Adèle d'Affry, duquesa de Castiglione Colonna que realizó su trabajo bajo el pseudónimo de "Marcello"-, analizándose los diferentes contextos y circunstancias que rodearon la vida y la creación artística de cada una de ellas.

En segundo lugar, las investigaciones de la profesora Olmedo Sánchez sobre mujer, arte y vida cotidiana, durante la realización del proyecto. Los resultados de las mismas han sido publicados en 2017 y 2019 (recogidos en el apartado Referencias), hallándose todavía en prensa otros estudios sobre esta temática.

La intervención del Dr. Mellado Calderón, colaborador honorario del Departamento de Historia del Arte, Arqueología y Música, durante el curso académico 2017-2018, se ha enmarcado en las actividades prácticas de la asignatura Artes Decorativas y Aplicadas entre los siglos XV-XVIII. Su labor se ha centrado en la joyería y su vinculación con la moda femenina. Dicho tema fue impartido en una sesión práctica con la explicación de diversas tipologías de joyas empleadas por las mujeres durante la Edad Moderna, como expresión de ostentación (joyas de pecho, petos, pendientes) y poder (aderezos, tiaras, coronas, etc.), en consonancia con el ámbito público por el que dichas féminas transitan. Algunas de estas joyas se han conservado en nuestro país gracias a las donaciones efectuadas por miembros de la elite social a imágenes marianas, como exvotos, por algunos hechos significativos.

El profesor González Torrico ha realizado las siguientes las aportaciones al proyecto de innovación docente en relación a la asignatura El Conocimiento del Medio Social y Cultural, materia obligatoria del primer curso del Grado de Educación Primaria, impartida en el Centro de Magisterio Sagrado Corazón, adscrito a la Universidad de Córdoba. En el desarrollo de la misma ha analizado con los discentes la situación de la mujer desde la Edad Media hasta el siglo XIX, desarrollando los contenidos teóricos-prácticos según se ajustan al programa. A este respecto, ha comparado entre sí las diversas formas de discriminación y exclusión sociales dadas durante las etapas históricas tratadas. Asimismo, ha expuesto los ejemplos de convivencia, tolerancia e integración que se dieron, identificando los principales hitos 
de la evolución de la situación de la mujer durante la Edad Media, Moderna y Contemporánea, exponiendo sus condiciones de vida, sus esquemas de relación con el sexo masculino y sus aportaciones a los planos político, económico, social y cultural. Para la aplicación de lo expuesto, ha realizado con todos los temas de la asignatura el dossier de materiales que constituye la base principal del trabajo del docente y del alumnado, en y fuera del aula, con bibliografía específica del tema en cuestión. Ha elaborado también el esquema básico que se desarrolla en clase, más o menos amplio, dependiendo de las cuestiones a estudiar.

En segundo lugar, el alumnado ha realizado un trabajo de manera cooperativa sobre diferentes personajes históricos relevantes del siglo XV (Isabel I de Castilla, Juana I de Castilla y Juana la Beltraneja), haciendo uso de la tecnologías de la información y comunicación de que dispone el centro de Magisterio Sagrado Corazón, así como de una bibliografía recomendada. En dicha actividad se ha pretendido recalcar el papel de la mujer en esta época y cómo estas tres féminas fueron un punto de inflexión, especialmente la primera, teniendo en cuenta la situación de las mujeres a todos los niveles durante esta etapa histórica. Una vez finalizado el trabajo, el alumnado ha expuestos sus propios resultados con la presentación de su propia visión y ha efectuado una valoración sobre la situación de la mujer desde la perspectiva de género durante este periodo histórico. Esta actividad ha sido evaluada como un instrumento de trabajo grupal.

El alumnado ha realizado también una visita guiada por el docente a la Catedral de Córdoba, así como a diversas iglesias y monasterios de la capital cordobesa, dentro del tema específico de patrimonio andaluz que contiene esta asignatura. En dicha visita se ha visto el proceso de constitución de las diversas capillas y altares que hay en estos recintos religiosos, como lugar de enteramiento de hombres y mujeres de las distintas épocas históricas estudiadas y la mayor presencia de hombre que de mujeres dentro del recinto catedralicio, en detrimento de otros edificios religiosos donde hay mayor presencia de mujeres. Esta visión o actitud hacia la muerte ha sido estudiada también dentro de una de las competencias de la asignatura: Conocer las diferentes manifestaciones a las que ha dado lugar el hecho religioso a lo largo de la historia y su relación con la cultura, analizando, pues, una de las corrientes historiográficas de moda en el siglo XX sobre la historia de las mentalidades.

En otra de las actividades programadas los discentes han visualizado y analizado materiales filmográficos, concretamente la película Germinal del director Claude Berri (1993), adaptación de la novela homónima de Emile Zola (1885). La revolución industrial dio lugar a la creación de una sociedad desigual dominada por la burguesía, que fundamentaba su riqueza en el dominio de la tecnología y en el trabajo de otro grupo social: el proletariado. Las desigualdades sociales y las duras condiciones de vida impuestas a los trabajadores determinaron la formación del Movimiento Obrero, cuyos objetivos eran la conquista de unas mejores condiciones laborales, la protección ante los abusos empresariales y, en último extremo, la transformación de la sociedad. Estas son las líneas principales que se abordan en esta película, en la que ha sido analizado el papel concreto de la mujer: su incorporación al mundo laboral y cómo se convierte en una pieza fundamental para el sostenimiento del eje familiar, más allá del trabajo masculino que impone el género en la organización genuinamente patriarcal de la sociedad preindustrial. El alumnado ha valorado todos los aspectos anteriormente expuestos y ha analizado de manera pormenorizada la situación de la mujer en esta etapa de la industrialización con 
respecto a la situación actual. Esta actividad ha sido evaluada como un instrumento de trabajo individual.

Por último, el profesor Martínez Romera ha aplicado el proyecto de innovación docente en las siguientes asignaturas impartidas en la Universidad de Málaga: Educación para la Ciudadanía, correspondiente al Grado de Educación Primaria; e Innovación del Master de Segundaria. En el caso de Educación para la Ciudadanía, entroncando con el desarrollo curricular de la asignatura respecto a las cuestiones de igualdad y género que tienen su base en la carta universal de los derechos humanos, se ha planteado una experiencia que pone de relieve tanto la necesidad y vigencia de las cuestiones relativas a la igualdad entre sexos, así como la búsqueda del desarrollo de un pensamiento crítico al respecto, entendiendo por éste, la capacidad de cribar argumentos y construir posiciones propias a partir de las fuentes; algo que constituye la base formativa de la Educación Primaria.

Se ha partido de la intervención de una ponente de TEDTalk de reconocida proyección internacional, pero no exenta de controversia: Laura Bates, quien da a conocer su proyecto Everyday sexism. En el mismo recopila, a través de un portal online, experiencias y testimonios de mujeres que han vivido agravios o situaciones de acoso en base a su condición sexual. A partir de ahí, la autora hila un discurso reivindicativo que sirve de marco teórico para legitimar su iniciativa y su expansión. El número de testimonios es muy significativo.

Partiendo de toda esta base se ha pedido al alumnado la realización de un visionado crítico de la charla, reflejando posiciones comunes, discrepantes o de duda. La experiencia ha puesto de manifiesto la buena acogida de la iniciativa, si bien también ha puesto sobre la mesa algunas zonas grises respecto a lo que constituye un ejercicio de agravio y acoso por cuestión de sexo. Debate que, más allá de las connotaciones propias del marco feminista, obliga al alumnado a tener que argumentar de forma razonada y constructiva sus posturas. Motivo por el que la experiencia se considera satisfactoria, si bien necesaria de mayor continuidad temporal y transversal (resto de materias).

Respecto a la asignatura Innovación del Máster de Profesorado, el énfasis ha sido metodológico. Además se ha tenido en cuenta que, dada la mayor edad de los discentes y la presumible mayor solidez intelectual de los planteamientos, se ha optado por un material claramente provocador. En tal sentido, se ha analizado una pequeña charla de Cassie Jaye, una reconocida activista del movimiento feminista que en 2016 realizó el controvertido documental "La Píldora Roja", con el que pretendía inicialmente desacreditar el movimiento por los derechos del hombre (EEUU), y que finalmente adquirió tiente autobiográficos para servir de ventana a su proceso para el abandono del movimiento feminista. Como era de suponer, la controversia ha estado servida, siendo relativamente homogénea, con una oposición generalizada respecto a las tesis defendidas por la autora, que en no pocas ocasiones, y para nuestra sorpresa, adolecen de la necesaria argumentación. Han sido más frecuentes de lo esperado las falacias lógicas, tal vez por un exceso de reacción visceral, y han resultado menos abundantes de lo esperado los análisis minuciosos y razonados. En ambos casos, en las fases de debate se ha contado con los testimonios de mujeres que han decidido aportar su visión, tanto como prueba de la situación de agravio y acoso que viven las mujeres como también de situaciones en las que esto no es así (hermanos, padres, parejas). Con momentos de gran tensión. No obstante, que dicha diversidad se reflejara en el aula y se vivieran conminados a entenderse, a encontrar elementos comunes de convivencia, no es algo solo pertinente sino además necesario en el momento actual. 


\section{RESULTADOS}

Los resultados obtenidos en cada una de las disciplinas contempladas en el proyecto de innovación docente han sido muy satisfactorios. A la diversidad de enfoques con la que ha sido abordada la temática del proyecto hay que sumar la positiva actitud del alumnado en la recepción de tales contenidos, siendo igualmente enriquecedoras sus aportaciones al respecto. El interés del alumnado por esta temática constituye todo un aliciente, dada la intención previa de publicar los resultados del proyecto en un estudio más amplio, tarea en la que actualmente se hayan trabajando los miembros integrantes del mismo. En cualquier caso, la certeza en la obtención de una respuesta óptima por parte del alumnado quedaba avalada de antemano, a tenor de la buena acogida de los referidos proyectos innovación docente en cursos anteriores y las experiencias adquiridas en relación a los mismos.

Los resultados alcanzados en la asignatura impartida por la profesora Gómez Navarro en el proyecto han sido importantes para el alumnado y satisfactorios para la docente, porque han permitido palpar, testar y analizar de forma concreta la diferencialidad que impone el género en la organización genuinamente patriarcal de la sociedad preindustrial. Las conclusiones obtenidas al respecto posibilitarán profundizar en las observaciones que la experiencia ha proporcionado y, en su caso, mejorar las que así lo precisen.

En la asignatura impartida por la profesora Manchado López, el alumnado ha asistido regularmente a las clases y su grado de implicación con la asignatura ha sido importante, tal y como refleja el alto número de aprobados y las calificaciones obtenidas. La dinámica activa de la docencia y la ya mencionada implicación e interés de los alumnos, ha favorecido el desarrollo de la actividad docente. Los resultados más relevantes de la actividad realizada son los siguientes:

1. Conocimiento de la normativa legal y las prácticas sociales que regulaban la vida familiar de los grupos dominantes de la sociedad española de Manila en los siglos XVI y XVII.

2. Conocimiento del papel que jugaba la mujer en la sociedad de la época y sus posibilidades de tomar decisiones autónomas (proyectos matrimoniales).

3. Conocimiento de la existencia de fenómenos de violencia contra la mujer y de la forma en que la sociedad los valoraba.

4. El tratamiento de los temas abordados a través de fuentes primarias es uno de los aspectos más destacables de esta actividad, ya que resulta enormemente atractivo para los alumnos.

Los satisfactorios resultados de las actividades realizadas en el aula por la profesora Olmedo Sánchez se pueden resumir en los siguientes puntos:

1. La aproximación al conocimiento de la proyección de la mujer perteneciente a la elite social novohispana, durante el siglo XVIII, a través de la pintura.

2. La profundización, mediante la pintura y la escultura, del papel asumido por las mujeres en el marco de la sociedad a comienzos de la época contemporánea (desde finales del siglo XVIII a principios del siglo XX), con especial atención a las mujeres artistas. El expreso interés sobre este último punto por parte del alumnado ha llevado a la profesora a completar en los siguientes cursos académicos la materia teórica de la asignatura $\mathrm{La}$ 
génesis del arte contemporáneo, con el estudio de aquellas pintoras y escultoras más destacadas en los comienzos de la contemporaneidad.

3. El conocimiento, a través de las artes decorativas, de la activa participación de algunas mujeres de la elite social en calidad de mecenas y la importancia concedida por las mismas a dichas manifestaciones artísticas en relación a su imagen pública.

La actividad práctica impartida por el Dr. Mellado Calderón en la asignatura de Artes decorativas y aplicadas entre los siglos XV y XVIII, ha sido el gran interés para los discentes. Tratándose de una materia prácticamente desconocida para el alumnado, ha permitido la apertura de nuevos horizontes, ofreciendo diversas posibilidades estudio y de investigación.

Los resultados obtenidos por el profesor González Torrico, han sido igualmente muy satisfactorios, tanto para el docente como para el alumnado, ya que se ha dado un enfoque del género durante el curso académico a la asignatura El Conocimiento del Medio Social y Cultural. Las conclusiones obtenidas al respecto también han posibilitado profundizar algunas observaciones expresadas por el propio alumnado:

1. Influencia política y social que ejercieron algunas mujeres de la realeza castellana durante la Edad Moderna.

2. Igualdad o diferencias de condiciones de hombres y mujeres en el momento de su muerte.

3. Importancia que adquirió la mujer durante la revolución industrial.

Finalmente, las actividades planteadas por el profesor Martínez Romera también han tenido una excelente acogida. Los resultados de la aplicación del presente proyecto en el aula, han sido publicados en un artículo (recogido en el apartado Referencias). En cualquier caso, el alumnado del Grado de Educación Infantil que ha participado en la experiencia ha mostrado conciencia activa, alerta, pero no organizada y definida respecto al sexismo. Por ello, es necesario seguir profundizando en estrategias didácticas que permitan la enseñanza de las corrientes de pensamiento y movilización social contemporáneas, de una forma detallada conceptualmente y abierta ideológicamente, en tanto que, como docentes, nunca se ha de perder de vista que el compromiso de hacer aprehensible el conocimiento a las nuevas generaciones, pero no imponer juicios al respecto.

\section{CONCLUSIONES}

A modo de conclusión, se subrayan las siguientes ideas:

Partiendo del reconocimiento alcanzado por los estudios de mujeres en el ámbito de la investigación (pese a que todavía quede mucho por consolidar), debería ir a la par la importancia de esta temática en el ámbito de la enseñanza en general y, en concreto, en la docencia universitaria. El presente proyecto supone una pequeña contribución en tal sentido.

La necesidad de plantear los estudios de mujeres desde la transversalidad que permiten distintas disciplinas. Las perspectivas ofrecidas por Historia Moderna, la Historia de América, la Historia del Arte y la Didáctica de las Ciencias Sociales, disciplinas que han integrado dicho proyecto, constituyen un marco idóeno para el estudio del creciente protagonismo asumido por las mujeres desde las centurias modernas a la contemporaneidad

Existiendo numerosísimos aspectos relacionados con la mujer, que tan sólo han podido ser esbozados y que precisan de un planteamiento más profundo, la experiencia obtenida en el presente proyecto constituye un punto de partida para seguir ahondando en futuras iniciativas de innovación docente, que permitan plantear en el aula nuevas perspectivas sobre los estudios de género. 


\section{REFERENCIAS}

Alva Rodríguez, I. (1997). La vida municipal en Manila (siglos XVI y XVII). Córdoba: Universidad de Córdoba.

Amelang, J.S., Nash, M. (eds) (1990). Historia y género: las mujeres en la Europa moderna y contemporánea. Valencia: Institució Alfons el Magnánim.

Anderson, B.S., Zinsser, J.P. (1991). Historia de las mujeres. Una historia propia. Barcelona: Crítica.

Aranda Huete, A. (2000). Aspectos tipológicos de la joyería femenina española durante el reinado de Felipe V. Anales de Historia del Arte, 10, 215-245.

Aranda Huete, A. (2006). Joyas de Fernando VI y Bárbara de Braganza. Rivas Carmona J. (ed.) Estudios de platería: San Eloy (pp. 21-44) Murcia: Universidad de Murcia.

Barrionuevo Pérez, R. (2011). Escultoras en su contexto. Cuatro siglos ocho historias. Madrid: Visión Libros.

Bertrand, M. (1999). Élites, parentesco y relaciones sociales en Nueva España. Tiempos de América. Revista de Historia, Cultura y Territorio, 3-4, 57-66.

Birriel Salcedo, M. (coord.) (1992). Nuevas preguntas, nuevas miradas. Fuentes y documentación para la Historia de las Mujeres (siglos XIII-XVIII). Granada: Universidad de Granada.

Bolufer Peruga, M., Morante Deusa, I. et al. (2008). Mujeres y modernización. Estrategias culturales y prácticas sociales (siglos XVIII-XX). Madrid: Insitituto de la Mujer.

Cámara Marín, S. (2014). Análisis de la cultura de género en el ámbito educativo, Lisboa, 2014- Dissertações de Mestrado. (Dissertação apresentada para cumprimento dos requisitos necessários à obtenção do grau de Mestre em Estudos sobre as Mulheres). URI: http://hdl.handle.net/10362/13919

Carmona Escalera, C. (2012). El cuerpo femenino en las obras de Egon Schiele y de Gustav Klimt. Thémata. Revista de Filosofía, 46, 667- 673. Recuperado de https://revistascientificas.us.es/index.php/themata/article/view/440/406

Casey, J., et al. (1987). La familia en la España mediterránea: siglos XV-XIX. Barcelona: Crítica.

Caso, A. (2016). Ellas mismas. Autorretratos de mujeres. Oviedo: Libros de la letra azul.

Díaz Sánchez, P., Franco Rubio, G. y Fuente Pérez, M.J. (eds.) (2012). Impulsando la historia desde la historia de las mujeres. Huelva: Universidad de Huelva.

Diego, E. de (1987). La mujer y la pintura del XIX español. (Cuatrocientas olvidadas y algunas más). Madrid: Cátedra.

Díez Jorge, M. E. (ed.) (2015). Arquitectura y mujeres en la historia. Madrid: Síntesis.

Domínguez Ortiz, A. (1988). El Antiguo Régimen: los Reyes Católicos y los Austrias. Madrid: Alianza.

Duby, G. y Perrot, M. (dirs.) (1993). Historia de las mujeres en Occidente, vol. 4. Madrid: Taurus.

Farge, A., Zemon Davis, N. (dirs.) (1992). Historia de las mujeres en Occidente, vol. 3. Madrid, 1992.

Fernández Álvarez, M. (2003). Isabel la Católica. Madrid: Espasa Calpe.

García-Abásolo, A. (2008). Formas de alteración social en Filipinas. Manila, escenario urbano de dramas personales. En Luque-Talaván, M., Manchado López M. M. 
(coord. y ed.). Un océano de intercambios: Hispanoasia (1521-1898). Homenaje al Profesor Leoncio Cabrero Fernández (pp. 255-283). Madrid: Ministerio de Asuntos Exteriores.

Garrido Ramos, B. (2014). La primera dama del Renacimiento: Isabella d'Este (14741539), promotora artística y mecenas. Revista Historias del Orbis Terrarum. Anejos de Estudios Clásicos, Medievales y Renacentistas, 8, 24-68. Recuperado de https://www.aacademica.org/beatriz.garrido.ramos/3

Gómez Navarro, S. (1994). Contribución de la documentación notarial al conocimiento del monacato femenino de la Edad Moderna. Las escrituras de dote de monjas en la Córdoba del Antiguo al Nuevo Régimen. Canterla C. (coord.). La mujer en los siglos XVIII y XIX (pp. 221-229). Cádiz: Universidad de Cádiz.

Gómez Navarro, S. (2004). A punto de profesar: Las dotes de monjas en la España Moderna. Una propuesta metodológica. En Javier Campos y Fernández de Sevilla, J. La clausura femenina en España: Historia de una fidelidad secular (pp. 83-94). San Lorenzo del Escorial: Publicaciones del RCU Escorial-Ma Cristina.

Gómez Navarro, S. (2011). De rejas adentro: monjas y religiosas en la España moderna. Una historia de diferencias en la igualdad. Revista de Historia Moderna. Anales de la Universidad de Alicante, 29, 205-227.

Gómez Navarro, S. (2017). Cenobios femeninos de la España barroca: Una mirada desde la historia social y del género. En Revenga Domínguez, P. (coord.). Arte barroco y vida cotidiana en el mundo hispánico. Entre lo sacro y lo profano (pp. 279-300). México-España: El Colegio de Michoacán A.C. UCO Press Editorial Universidad de Córdoba.

Gómez Navarro, S. (2017). Santa Clara de Montilla: ser convento femenino en la Iglesia española del Antiguo Régimen. En I-II Jornadas sobre el Convento de Santa Clara, un enclave a conservar (pp. 45-68). Montilla: Amigos de Santa Clara.

Gómez Navarro, S. (2018). Una escritura poco edificante pero muy necesaria: contabilidades de monjas y religiosas en la España Moderna (Córdoba del Antiguo al Nuevo Régimen). En Henar Gallego Franco, H. y García Herrero, M.C. (eds.). Autoridad, poder e influencia. Mujeres que hacen historia (pp. 541554). Barcelona: Icaria.

Gómez Navarro, S. (2019). Espiritualidad y religiosidad en la España de la II marquesa de Priego. En de Castro Peña, I. (coord.). Doña Catalina Fernández de Córdoba y Enríquez. $V$ Centenario de la toma de posesión del Marquesado de Priego (1517-2017) (pp. 117-148). Montilla: Ayuntamiento de Montilla.

Horcajo Palomero, N. (2010). Reinas y joyas en la Europa del siglo XVI. En Rivas Carmona J. (ed.). Estudios de platería: San Eloy (pp. 319-337). Murcia: Universidad de Murcia.

López Fernández, M. (2006). La imagen de la mujer en la pintura española 1890-1914. Madrid: La balsa de la Medusa.

Manchado López, M. Ma․ (2006). Poder y redes de influencia. Las trayectorias de una familia española en Filipinas (1596-1650). Revista de Indias, LXVI (238), 629-658.

Manchado López, M. Ma․ (2006). Adulterio y relaciones de poder en la Manila del siglo XVII. En Sánchez Baena, J.J.; Provencio Garrigós, L. (eds.). El Mediterráneo y América (pp. 387-404). Murcia: Universidad de Murcia.

Manchado López, M. Ma․ (2008). Familias y estrategias matrimoniales en Manila a principios del siglo XVII. El caso del oidor Antonio de Ribera Maldonado. En Usunáriz Garayoa, J.M.; García Bourrellier, R. (coords.) Padres e hijos en España y el mundo hispánico. Siglos XVI y XVIII (pp. 125-158). Madrid: Visor.

Manchado López, M. Ma . (2009). Estrategias familiares en una sociedad de frontera: Manila (1571-1604). Francisco Chacón Jiménez, F., Hernández Franco, J. y 
García González, F. (coords.). Familia y organización social en Europa y América, siglos XV-XX (pp. 79-92) Murcia: Universidad de Murcia.

Manchado López, M. Mạ. (2015). Las controversias sobre el matrimonio de los miembros de la Audiencia de Manila y sus familiares (1583-1624). La boda del oidor viudo Madrid y Luna. Anuario de Estudios Americanos, 72 (1), 177-210.

Martínez Romera, D.D. (2019). Feminismo y percepción del sexismo mediante TIC en educación superior. Un estudio de caso. Didáctica de las Ciencias Experimentales y Sociales, 36, 3-16. DOI:10.7203/DCES.36.12634

Mayayo, P. (2003). Historias de mujeres, historias del arte. Madrid: Cátedra.

Megías Álvarez, M.J. (2007). Evolución de las joyas de pecho en el Barroco español: de la 'rosa' al 'peto'. En Rivas Carmona, J. (ed.). Estudios de platería: San Eloy (pp. 471-482). Murcia: Universidad de Murcia.

Megías Álvarez, M.J. (2008). Los petos en la joyería sevillana: nuevas aportaciones. En Rivas Carmona, J. (ed.), Estudios de platería: San Eloy (pp. 411-420). Murcia: Universidad de Murcia.

Morant Deusa, I. (dir.) (2005-2006). Historia de las mujeres en España y América Latina, I-IV. Madrid: Cátedra.

Muñoz López, P. (2003). Mujeres españolas en las artes plásticas. Pintura y escultura. Madrid: Síntesis.

Nash, M. (2010). Mujeres en el mundo: historia, retos y movimientos. Madrid: Alianza.

Nogueira, L., Nogueira, M., Navarro J. M. \& Lizcano, E. (2015). Metodología de las ciencias sociales. Barcelona: Tecnos.

Núñez Méndez, E. (2006). Representando a la mujer de elite: el diálogo entre el retrato y a pintura de género en los interiores domésticos novohispanos. Revista Kaypunku, 3 (2), 15-55. Recuperado de: https://es.scribd.com/document/323463290/Representando-a-la-mujer-de-eliteel-dialogo-entre-el-retrato-y-la-pintura-de-genero-en-los-interiores-domesticosnovohispanos

Olmedo Sánchez, Y. V. (2017). Mujer y arte en la vida cotidiana de la España barroca. En Paula Revenga Domínguez, P. (coord.), Arte barroco y vida cotidiana en el mundo hispánico. Entre lo sacro y lo profano (pp. 369-389). México-España: El Colegio de Michoacán A.C.-UCOPress Editorial de la Universidad de Córdoba.

Olmedo Sánchez, Y. V. (2019). Mujeres y arquitectura en Lucena a mediados del siglo XVIII: datos a través del Catastro de Ensenada. Tiempos Modernos. Revista Electrónica de Historia Moderna, 9 (38), 164-175. Recuperado de: http://www.tiemposmodernos.org/tm3/index.php/tm/article/view/5371/831

Palmer, R. y Colton, J. (1990). Historia Contemporánea. Madrid: Akal.

Pérez Ochando, L. y Alba Pagán, E. (eds.) (2015). Me veo luego existo: Mujeres que representan, mujeres representadas. Madrid: Consejo Superior de Investigaciones Científicas.

Ramos, Ma. D. (1993). Mujeres e historia. Reflexiones sobre las experiencias vividas en los espacios públicos y privados. Málaga: Universidad de Málaga.

Sauret Guerrero, T. (coord.) (1996). Historia del Arte y Mujeres. Málaga: Universidad de Málaga.

Sauret Guerrero, T. y Quiles Faz, A. (eds.) (2002). Luchas de género en la Historia a través de la imagen. Málaga: Diputación de Málaga, Centro de Ediciones de la Diputación de Málaga.

Vigil, M. (1986). La vida de las mujeres en los siglos XVI y XVII. Madrid: Siglo XXI de España. 